\title{
el entretenimiento preventivo de la maquinania y el material
}

Un descuido pequeño puede originar un perivicio grande.-Franklin

\section{sinopsis}

$860-1$

La creación de un sentido de entretenimiento preventivo requiere ser llevada a la mente de los usuarios, con el fin de que la reparación de las pequeñas irregularidades que puedan presentarse en la maquinaria sean subsanadas rápidamente antes de que las mismas puedan originar averías mayores. El enıretenimiento de la maquinaria exige una continuidad y atención a la que se oponen diversos factores, tales como: el aburrimiento, la escasez de medios, el sentido de falso entretenimiento, el acaparamiento, el canibalismo, un falso sentido de orgullo por parte del usuario de lograr que las máquinas funcionen, aun en malas condiciones, etc. Por lo tanto, $y$ antes de preocuparse de las labores concretas correspondientes a cada tipo de maquinaria, es preciso convencerlos de lo favorable e indispensable que resulta dicho entretenimiento, mediante el empleo de los diversos medios e incentivos que puedan ser utilizados.

\section{capitulo}

\section{Qué puede antenderse por "Entreteminniemto prevemtivo"}

El Diccionario de Términos del Ejército de los Estados Unidos lo define como: "Los cuidados y servicios de mantenimiento por parte del personal usuario, para conservar el material en buenas condiciones de servicio mediante la inspección sistemática y la detección previa y remedio de los fallos incipientes, bien antes que ocurran o, por lo menos, antes de que originen deficiencias más graves."

El escalón de una Empresa u Organización que tiene a su cargo realizar obras de construcción, etc., no debe dedicarse a la reparación o a la reconstrucción de la maquinaria puesta a su servicio y, por consiguiente, será preciso disponer un escalón técnico superior que tenga a su cargo la reparación y conservación de las máquinas y vehículos, bien por sí mismo, o trasladándolos a los lugares convenientes.

No quiere decir esto que el usuario deba usar la máquina hasta que se rompa, ya que todo el sistema debe descansar sobre la premisa fundamental de que el material no se queja, como el factor humano, y que, por lo tanto, deberá vigilarse y cuidarse por los que lo utilizan con el fin de evitar y subsanar hasta "los principios de avería".

La figura geométrica que ha de presidir en toda organización que emplea maquinaria, correspondiente al entretenimiento del material, debiera ser un triángulo, en el que, por fajas, estuvieran localizadas las distintas fases del entretenimiento, de acuerdo con su número y con la frecuencia conque deben ser efectuadas, estando la importancia de las mismas y los beneficios que reportan en relación directa con su proximidad a la base.

Tareas de entretenimiento que debe ejecutar la dotación que usa el material.

Tareas que exigen preparación técnica y que deben ser realizadas por mecánicos especialistas.

Reparaciones que exigen especialización y herramientas adecuadas, pero que pueden ser ejecutadas por equipos móviles de reparación.

Reparaciones que hay que efectuar en un centro o taller de la misma empresa.

Grandes reparaciones y trabajos de reconstrucción que normalmente habrán de llevarse a cabo en establecimientos especiales.

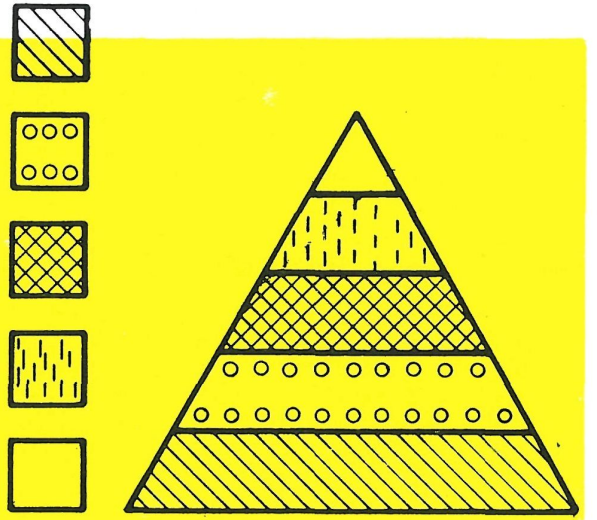

\section{Aspectos psicológicos del entretemimiento}

Existen varios factores, algunos favorables, pero en su mayoría negativos, que conviene tener presentes dada su influencia en el entretenimiento del material, entendiendo por tal, no sólo la maquinaria y vehículos, sino desde el material de oficina hasta las instalaciones de la Organización, vestuario, etc. 


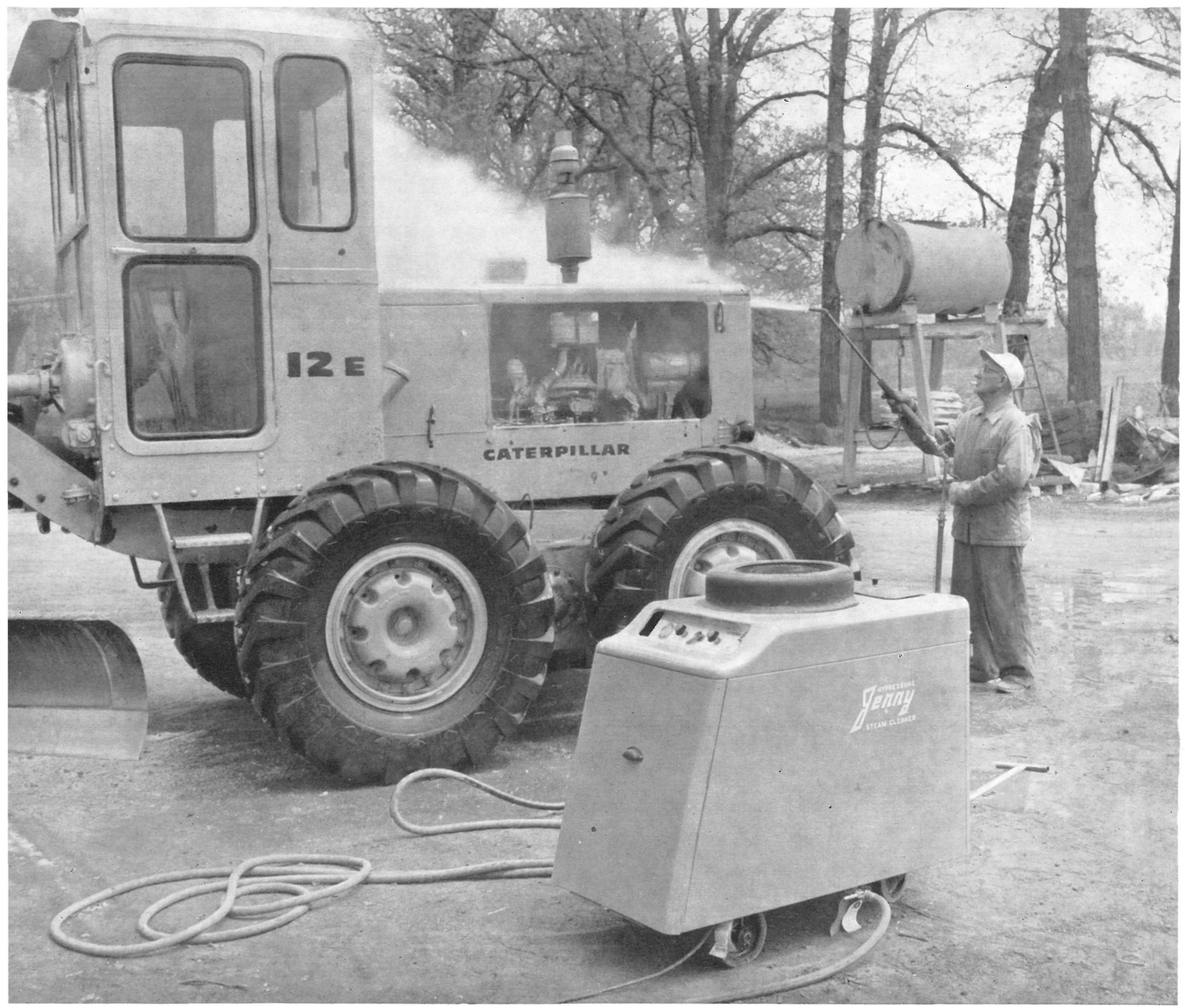

\section{Sentido de propiedad}

La idea generalizada de "bien común, bien de ningún", y la mentalidad generalizada de que el material solamente pertenece en sentido abstracto a aquel que lo usa, puede considerarse como el primer coeficiente negativo y la primera limitación para un empleo eficaz y un cuidado esmerado del mismo. Es difícil, efectivamente, imbuir la idea de que por cada uno debe sentirse el mismo sentido de orgullo y responsabilidad que por la propiedad privada y particular.

\section{El sentimiento de ser ignorado}

En realidad, es un sentido negativo, impreso en el individuo, el cual ve que sus superiores no se dan cuenta, normalmente, del buen uso que él hace del material puesto a su disposición, porque "dan por sentado" esto, cuando lo que debiera darse por hecho es que el entretenimiento tiende a cero, en la mayoría de los casos. 
Por otra parte, el operario tiene la convicción de que si su superior le ve repasando una máquina, va a pensar que algo no ha marchado correctamente cuando lo están corrigiendo $\mathrm{y}$, en el peor de los casos, que es una excusa del operario para no realizar otro trabajo.

\section{El problema del aburrimiento}

Indudablemente, se deriva una satisfacción al hacer funcionar un elemento mecánico, y esta satisfacción es aún mayor si nos lo dieron roto o estropeado; pero, en cambio, no se siente ninguna satisfacción semejante al evitar una rotura o una avería y, además, las labores de entretenimiento requieren continuamente idénticos trabajos que con frecuencia pueden resultar-y resultan-de una monotonía molesta.

\section{El complejo de presunción}

Se podría denominar el "contracomplejo de inferioridad". Mucha gente necesita afirmar su personalidad y sienten un imperioso deseo, instintivo, de lanzar humos, hacer ruidos y exigir y forzar al material hasta el límite de sus posibilidades.

Es muy probable-y sucede con frecuencia-que quienes manejan las máquinas les guste llamar la atención y que en muchos casos pretendan obtener de la maquinaria rendimientos, esfuerzos y trabajos para los que no ha sido construida.

\section{La tendencia a "cargar a otro el mochuelo»}

Es frecuente la actitud siguiente: "Ellos tienen el taller, las herramientas y los mecánicos. A nosotros nos toca romper, y a ellos arreglar lo que se rompa."

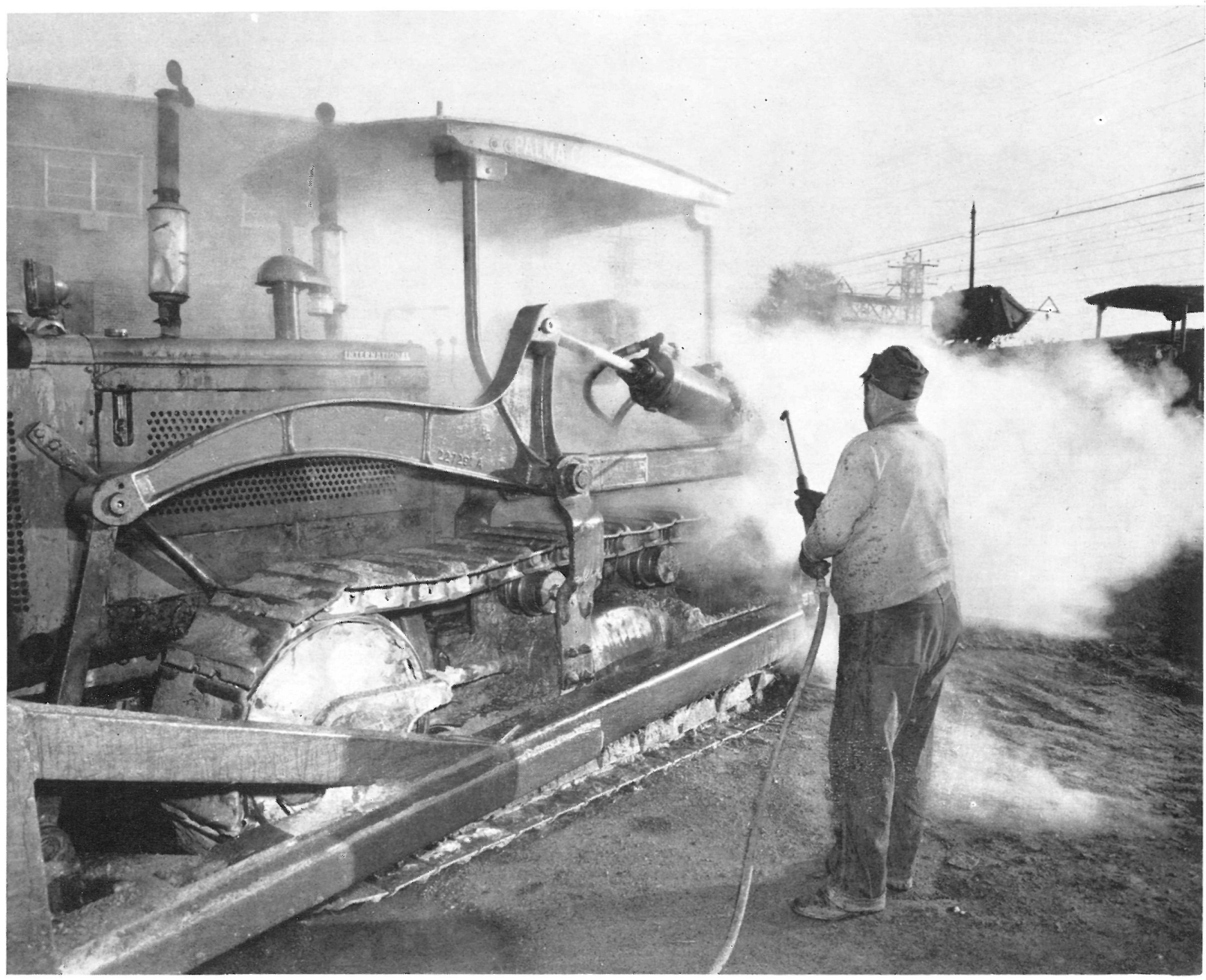




\section{El sentido de falsa economía}

Prácticamente, existe el concepto de que el entretenimiento, en contra de su objeto, es antieconómico, ya que exige unos gastos que en todas las organizaciones se intentan limitar y en muchas se rebajan hasta límites que lo hacen imposible e inútil, en la creencia de que son origen de caprichos y gastos superfluos, cuando no de filtraciones que deben evitarse.

\section{El entretenimiento ficticio}

El fenómeno es tan común, usual y normal, que no merece la pena de extenderse en la explicación del mismo. Consiste en encubrir las deficiencias, con la inmaculada limpieza de lo accesorio.

iCuántas revistas y visitas se habrán girado a parques de vehículos y maquinaria impecablemente alineados y pintados, y a talleres de entretenimiento con un bonito "escaparate" de herramientas, ficheros y gráficos, sin sospechar el visitante que el 50 por 100 del material estaba fuera de servicio!

\section{Falta de preparación del usuario}

Existen limitaciones, consecuencia de una falta de preparación técnica por parte del personal, que en muchos casos dificultan las labores de entretenimiento, pese a la buena voluntad y al interés del mismo, pero que por falta de conocimientos, tanto de lo que hay que hacer como del modo y de cuando debe realizarse, impiden que el interés del operario redunde en una provechosa labor de entretenimiento.

\section{El acaparamiento}

Lo más probable, si se efectúa una inspección, es encontrar una sorprendente variedad de repuestos, elementos y herramientas en los sitios más insospechados. Si se le pregunta al mecánico en cuestión, contestará: "Yo los acabo de coger por si le hacían falta." Estas piezas acaparadas faltan, indudablemente en el sitio oportuno, se estropean y deterioran inútilmente, y complican la contabilidad y el inventario de existencias.

\section{«El canibalismo»}

No es otra cosa que la utilización de material y piezas que están fuera de servicio, para utilizarlas en material y máquinas de la misma clase.

Este procedimiento ha sido siempre objeto de múltiples controversias, y el que más se ha prestado a discusiones en pro y en contra. Hay quienes están persuadidos de que es mejor tener una máquina o vehículo en uso que fuera de servicio. En realidad, la "canibalización" de una maquinaria desemboca fatal e invariablemente en su reducción al esqueleto, haciendo imposible prácticamente su recuperación.

Subsanar y remediar estas circunstancias desfavorables corresponde a todos los escalones, desde el usuario hasta el jefe; para ello será preciso, con carácter primordial, saber crear "el sentido del entretenimiento del material", mediante el acertado empleo de los medios de publicidad, emulación, recompensas y penalizaciones de que se pueda disponer.

\section{bibliografia}

Textos del curso "The Economics", del Industrial College of the Armed Forces.

“Terrassement a l'aide d'engins mécaniques”, M. Laruelle.

Traducción de "Preventive Maintenance Guide for Commanders of the U. S. Army". 


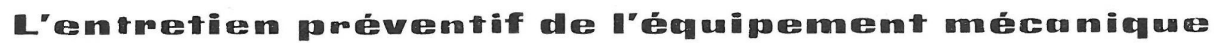

M. Chinchilla.

Un sentiment d'entretien préventif doit être inculqué à l'esprit des usagers pour que les réparations des petites irrégularités qui peuvent se présenter dans l'équipement mécanique, soient corrigées rapidement avant qu'elles puissent être à l'origine d'avaries de plus grande importance.

L'entretien de l'équipement mácanique exige une continuité et une attention auxquelles s'opposent divers facteurs, tels que: l'ennui, la pénurie de moyens, le sens de faux entretien, l'accaparement, le cannibalisme, un faux sens d'orgueil de la part de l'usager qui le pousse à faire fonctionner ses engins, même dans de mauvaises conditions.

Par conséquent et avant de se préoccuper de la mission concrète correspondant à chaque type d'engin, il est nécessaire de les convaincre de l'utilité et même de l'absolue nécessité de cet entretien et ceci par l'emploi de tous les moyens capables de les convaincre.

\section{Preventive upkeep of mechamical equipment}

M. Chinchilla.

Machinery users should develop a keen sense of preventive upkeep of their equipment, so that the slightest irregularities in the functioning of machinery shall be corrected before they can lead to more severe damage.

The efficient upkeep of machinery requires a continuity and attention which tends to be weakened by various factors, such as boredom, lack of money, a wrong idea about upkeep, the hoarding of spare parts, the destruction of one machine to repair another, a mistaken notion by the mechanic that a machine should be kept working as long as possible, even when it is working badly.

Consequently, before studying the specific functions of each type of machine, it is essential to emphasize how important it is to keep them in good repair, and incentives should be offered with that end in view.

\section{Fachgemeche Pficge von Maschinen zum Vombeugumg vom Sch äi dem}

M. Chinchilla.

Zur Vorbeugung von Schäden an Maschinenteilen ist es notwendig, im Bedienungsmann selbst einen Sinn für fachgerechte Pflege zu erwecken, um somit zu erreichen, dass die geringsten Unregelmässigkeiten und Störungen im Betrieb beobachtet und möglichst gleich beseitigt werden und grössere Schäden, die daraus entstehen können, vermieden werden.

Diese Pflege erfordert Beständigkeit und Aufmerksamkeit, die allerdings durch folgende Faktoren immer wieder leicht beeinflussbar sind: Langeweile, Mangel an Geld, falsche Pflege, das Hamstern von Ersatzteilen, das Auseinandernehmen einer Maschine zur Gewinnung von Teilen für den Bau mehrerer anderer, falscher Stolz seitens des Bedienungsmannes, der unbedingt erreichen will, dass seine Maschine auch unter schlechten Bedingungen funktioniert, etc.

Deshalb ist es notwendig, durch geeignete Mittel und geeigneten Ansporn, eine günstige Einstellung in diesem Sinne im Bedienungsmann zu erwecken, bevor überhaupt an die Erklärung der Handgriffe und des Funktionierens der Maschine selbst herangegangen werden kann. 